\title{
Effects of Different Interface Forms on Mechanical Properties of Steel Self-Compacting Concrete Composite Beams
}

\author{
Chengzhi Wang $(\mathbb{D}$, Xin Liu, Wei Liu, and Zhiming Li \\ Chongqing Jiaotong University, Chongqing 400074, China \\ Correspondence should be addressed to Chengzhi Wang; wangcz@cqjtu.edu.cn
}

Received 23 May 2020; Revised 25 June 2020; Accepted 20 July 2020; Published 3 August 2020

Academic Editor: Chiara Bedon

Copyright (c) 2020 Chengzhi Wang et al. This is an open access article distributed under the Creative Commons Attribution License, which permits unrestricted use, distribution, and reproduction in any medium, provided the original work is properly cited.

\begin{abstract}
In the water resources allocation project in Pearl River Delta, in order to optimize the structural design, the deep buried tunnel adopts the composite lining structure. However, the weakest link in a complex structure is the connection between two different interfaces. This paper reports the findings of an experimental study that was undertaken to investigate the interface mechanical performance of steel self-compacting concrete composite structure subjected to cyclic loads. In this study, different shear connectors are considered, and six different specimens were designed and tested, respectively. The test is used to research the effect of the different shear connectors on the bearing capacity and interface mechanical properties of composite structure in an experimental study. According to these test results, a detailed analysis was carried out on the relationships, such as the stress-strain and load-displacement relationships for the specimen. These tests show that the shear connectors will significantly enhance the bearing capacity and interface mechanical properties of the composite structure. Among them, the comprehensive performance of the specimens using the stud-longitudinal ribs shear connectors is the best. Additionally, a finite element analysis (FEA) model was developed. The comparison of the simulation results with the experimental results shows that this FEA is applicable for this type of experiment.
\end{abstract}

\section{Introduction}

This experiment takes the water resources allocation project in Pearl River Delta as the background, in which the deepburied tunnel accounts for $75 \%$ of the total length. The deepburied tunnel has the characteristics of large burial depth, long line length, and high internal and external water pressure, and the tunnel construction is in an extreme environment. Compared with ordinary tunnels, the high internal and external water pressures often cause the tunnels to be under extreme load conditions [1], and problems in water resources transportation will cause huge economic losses and difficult maintenance. So, the deep-buried tunnel is planned to adopt a new type of composite lining structure to combine the steel pipe with the segments, and the selfcompacting concrete is poured between the steel pipe and the segments to form a composite lining structure, as shown in Figure 1. However, the load transfer performance of the interface determines the overall bearing capacity of the composite lining structure. Therefore, it is necessary to carry out experimental research on mechanical properties of steelconcrete interface and optimize the interface connection mode to improve the overall bearing capacity of the structure.

In steel-concrete composite structures, the advantages of steel and concrete can be fully utilized, and shear connectors are directly related to the bearing capacity of the whole composite structure as the key part of the stress $[2,3]$. To ensure the rationality of design and the safe operation of steel-self compacting concrete composite structure, it is very urgent and necessary to study the mechanical properties of shear connectors $[4,5]$. Shear connector forms can be divided into three types: flange type, embedded type, and composite type [6,7]. Embedded connectors are seldom used in medium or longspan structures because of their inconvenience in construction. Flange connectors are very 


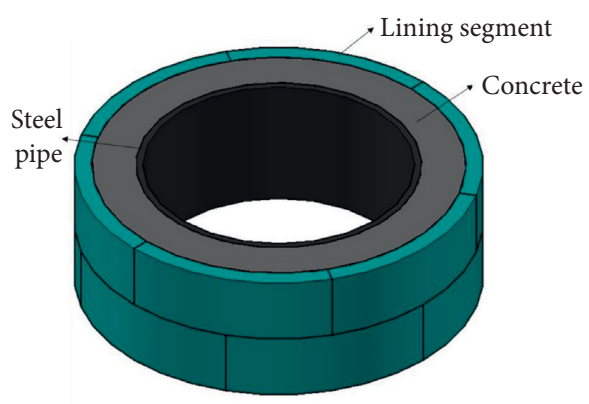

FIgURE 1: Diagram of composite lining.

popular among bridge designers due to their good bearing capacity, shear rigidity, and convenient construction $[8,9]$. Flange connectors mainly include stud connectors, angle connectors, and perfobond connector (PBL connector), and stud connectors and PBL connectors have been the most studied to date.

Stud connectors are widely used in bridges with smaller spans, and scholars have conducted many studies on them [10]. Viest [11] discussed the shear performance of stud connectors through push-out tests and gave the formula for calculating their shear capacities. Ollgaard et al. [12] carried out push-out tests with 48 groups of embedded connectors and put forward the formula for the shear capacity of these connectors. The experiments show that the shear strength of embedded connectors is mainly affected by the compressive strength and elastic modulus of concrete. Cederwall and $\mathrm{Li}$ [13] studied the shear resistance of studs in high strength and normal strength concrete, and the push-out test results showed that the concrete compression strength significantly affects the strength of the stud connections. Classen and Hegger [14] proposed models for the calculation of the slip capacity and the description of the shear-slip characteristic. The proposed models can be used for the characterization of the composite dowels' deformation capacity. Koop and Wolters [15] presented background information to the static design concept for composite dowels with clothoidal and puzzle shape regulated in the general technical approval and additionally presented the design formula for longitudinal static shear resistance. Valente and Cruz [16] conducted a comparative analysis of the performance of stud connectors, T-joints, and perforated plate joints. The test results show that the perforated plate joints have excellent performance in shear resistance and ductility. Vellasco PCGS and others $[17,18]$ made further improvement on the basis of PBL connector, that is, the combination of the perforated plate connector and the T-shaped connector. Through comparative analysis, it was found that the form connector performance is more outstanding.

In the design of composite lining structure, it is believed that the opening of the interface will lead to the failure of the structure. At present, similar projects lack reasonable design methods and can only adopt safe and conservative methods, which are not scientific and economical. Therefore, in order to improve the performance of the interface, it is necessary to comprehensively compare different interface processing methods and observe the mechanical properties and interface slippage properties of composite beams under different interfaces. Compared with the traditional single connection, the method of composite shear connection will be more economical and safe for the project, and there are few related researches at present. In order to compare the influence of different composite shear connectors on the bearing capacity of steel-self-compacting concrete composite beams, the interfacial mechanical properties of steelself-compacting concrete composite beams under reciprocating loads were studied in detail. At the same time, high performance concrete is gradually replacing ordinary concrete $[19,20]$, and the selection of self-compacting concrete has a high reference value for the practical application of future projects.

This paper mainly studies the mechanical properties of the steel-self-compacting concrete interface in the composite lining structure. Since the composite lining bears various loads together, the shear connectors need to transmit tensile force, shear force, and bending moment. At the same time, the tunnel involves repeated water filling and discharging; the change of water pressure is equivalent to repeated loading and unloading, so the test adopts the loading and unloading mode of reciprocating cycle. In order to fully study the mechanical properties of the steel-concrete interface, this study intends to start from the microscopic force mechanism of the interface and conduct the test of the bending and shear properties of the steel self-compacting concrete composite structure and study the behavioral characteristics of the steel-concrete interface under the cyclic loads. Through the above research, the connection mode of steel-concrete interface is optimized to improve the overall bearing capacity of the structure.

\section{Experimental Study}

2.1. Material Properties. All steel types used in the test are Q345C. According to the code GB/T 2975-2018 [21], Young's modulus of the steel $E$ is $201.5 \mathrm{GPa}$, and the yield strength of the steel $f_{y}$ is $337.16 \mathrm{MPa}$. The results are shown in Table 1.

The strength grade of self-compacting concrete is C30, the coarse aggregate is ordinary gravel, and the daily drinking water is mixed. All indexes of water quality meet the requirements of concrete mixing water. According to JGJ/T 98-2010 [22], the mix design of all test specimens is shown in Table 2. And the rheological properties of selfcompacting concrete are tested, as shown in Figure 2. At the same time, six standard test blocks were produced, the length, width, and height are $100 \mathrm{~mm}$, respectively, and the test pieces were placed in the required indoor curing (temperature: $20 \pm 2{ }^{\circ} \mathrm{C}$, humidity: $95 \%$ or more). After the curing is completed, the strength is measured on the pressure test machine, and the test results are shown in Table 3.

2.2. Test Specimen Design. In order to better study the force and interface failure characteristics of composite members, in this experiment, a total of 6 groups of steel self- 
TABLE 1: Mechanical properties of steel.

\begin{tabular}{lccc}
\hline Model & No. & $f_{y}(\mathrm{MPa})$ & $E_{s}(\mathrm{GPa})$ \\
\hline Q345C & 1 & 336.12 & 203 \\
Q345C & 2 & 338.20 & 200 \\
- & Ave. & 337.16 & 201.5 \\
\hline
\end{tabular}

TABle 2: Concrete mix design.

\begin{tabular}{lccccccc}
\hline Strength grade & $\begin{array}{c}\text { Water to cement } \\
\text { ratio (mass ratio) }\end{array}$ & $\begin{array}{c}\text { Water-reducing agent } \\
\left(\mathrm{kg} / \mathrm{m}^{3}\right)\end{array}$ & Cement $\left(\mathrm{kg} / \mathrm{m}^{3}\right)$ & $\begin{array}{c}\text { Water } \\
\left(\mathrm{kg} / \mathrm{m}^{3}\right)\end{array}$ & $\begin{array}{c}\text { Gravel } \\
\left(\mathrm{kg} / \mathrm{m}^{3}\right)\end{array}$ & $\begin{array}{c}\text { Sand } \\
\left(\mathrm{kg} / \mathrm{m}^{3}\right)\end{array}$ & $\begin{array}{c}\text { Rheological properties } \\
(\mathrm{mm})\end{array}$ \\
\hline C30 & 0.55 & 3.61 & 368.90 & 201.11 & 786.00 & 801.72 & 650 \\
\hline
\end{tabular}

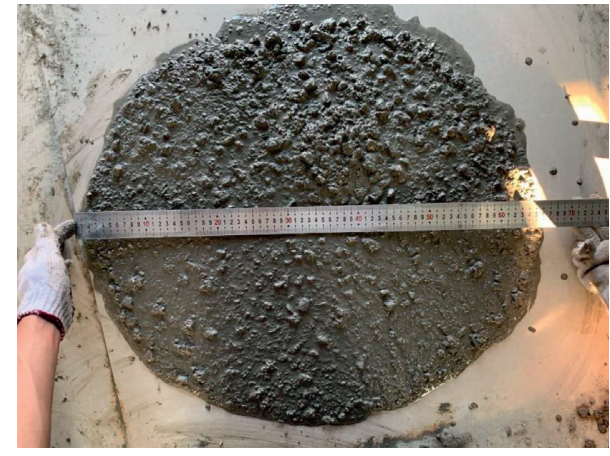

FIGURE 2: Rheological properties of concrete.

TABLE 3: Concrete strength.

\begin{tabular}{lcc}
\hline Time & $\begin{array}{c}\text { Maximum bearing } \\
\text { capacity }(\mathrm{kN})\end{array}$ & Specimen strength $(\mathrm{MPa})$ \\
\hline 7 days & 640.7 & 28.46 \\
14 days & 798.49 & 35.49 \\
28 days & 825.39 & 36.68 \\
\hline
\end{tabular}

compacting concrete composite structural specimens were designed for load test. The length of the specimen is $3000 \mathrm{~mm}$ and the width of the specimen is $800 \mathrm{~mm}$. The height of the specimen is $314 \mathrm{~mm}$, of which the thickness of the concrete is $300 \mathrm{~mm}$ and the thickness of the steel plate is $14 \mathrm{~mm}$. The model size is shown in Figure 3.

As summarized in Table 4, there are six specimens. The arrangement of shear connectors of each specimen is different. SP1 and SP2 use stud-longitudinal ribs shear connectors, SP3 uses reinforcing bars-longitudinal ribs shear connectors, SP4 uses transverse rib-longitudinal ribs shear connectors, SP5 uses longitudinal ribs shear connectors, and SP6 uses two longitudinal ribs shear connectors. The layout of the specimen is shown in Figure 4.

2.3. Test Setup and Instrumentation. The test setup and instrumentation for the specimens are presented schematically in Figure 5. One servohydraulic actuator with loading capacities of $500 \mathrm{kN}$ was used in the loading frame, which allows lateral forces to be applied to the dowel bar.

This experiment adopts the method of hierarchical loading. Before the loading test, preloading is carried out to

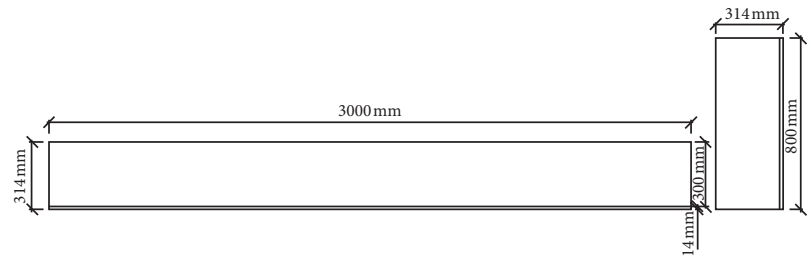

Figure 3: Specimen size.

determine whether the beam is loaded eccentrically. At the same time, check the readings of each device, confirm that the displacement gauge and strain gauge data are in good condition, and unload to zero. After the completion of preloading, the graded reciprocating loading is started. Before concrete cracking, the load control level is $20 \mathrm{kN}$; after concrete cracking, the load control level is $50 \mathrm{kN}$. The loading method adopts the reciprocating loading methods of $5-50 \mathrm{kN}, 5-100 \mathrm{kN}, 5-150 \mathrm{kN}, 5-200 \mathrm{kN}, 5-250 \mathrm{kN}$, and $5-300 \mathrm{kN}$. After cyclic loading for 5 times in each stage, the load increases to the cycle of the next stage until the specimen is destroyed.

Displacement meter and strain gauge were used for data collection. Four strain gauges were arranged from top to bottom at both ends of the specimen and at the side of the specimen mid-span. Three strain gauges were arranged in each column at the bottom, middle, and both ends of the specimen. Displacement measurement using displacement meter is shown in Figure 6(a). The deformation is measured by using dial indicators at the lower center and both ends of the specimen. The measuring range of the instrument is 0 to $50 \mathrm{~mm}$, and the maximum measurement accuracy is $0.01 \mathrm{~mm}$. The instrument can measure the absolute displacement and the relative displacement of the middle of the pile. In order to obtain the transverse displacement of concrete under compression, three transverse displacement meters are placed below the side of the beam at the mid-span position and at the axes of both sides. The experimental device schematic and strain gauge point position map are shown in Figures 6(b) and 6(c).

\section{Results and Discussion}

This section presents the main experimental results of the tested steel self-compacting concrete beams, including the failure modes, mid-span load deflection, load-strain 
Table 4: Details of the specimens.

\begin{tabular}{lcccccc}
\hline Specimen no. & $H(\mathrm{~mm})$ & $w(\mathrm{~mm})$ & $L(\mathrm{~mm})$ & Types of shear connectors & $f_{\mathrm{cu}}^{1}(\mathrm{MPa})$ & $f_{y}^{2}(\mathrm{MPa})$ \\
\hline SP1 & 314 & 800 & 3000 & Studs, longitudinal ribs & 36.68 & 337.16 \\
SP2 & 314 & 800 & 3000 & Sparse studs, longitudinal ribs & 36.68 & 337.16 \\
SP3 & 314 & 800 & 3000 & Reinforcing cage, longitudinal ribs & 36.68 \\
SP4 & 314 & 800 & 3000 & Longitudinal ribs, transverse ribs & 36.68 & 337.16 \\
SP5 & 314 & 800 & 3000 & Longitudinal ribs & 337.16 \\
SP6 & 314 & 800 & 3000 & Two longitudinal ribs & 36.68 \\
\hline
\end{tabular}

${ }^{1} f_{\text {cu }}$ : concrete cube compressive strength and ${ }^{2} f_{y}$ : yield strength of steel.
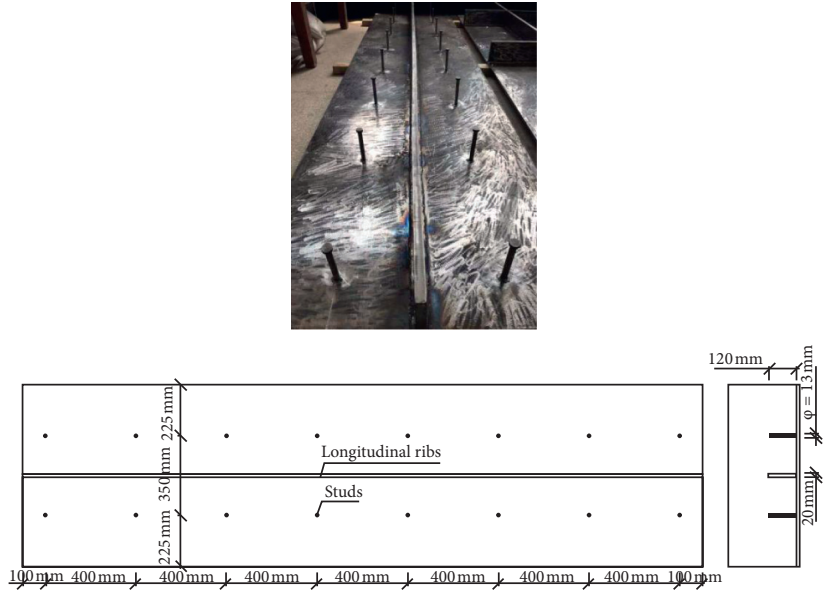

(a)
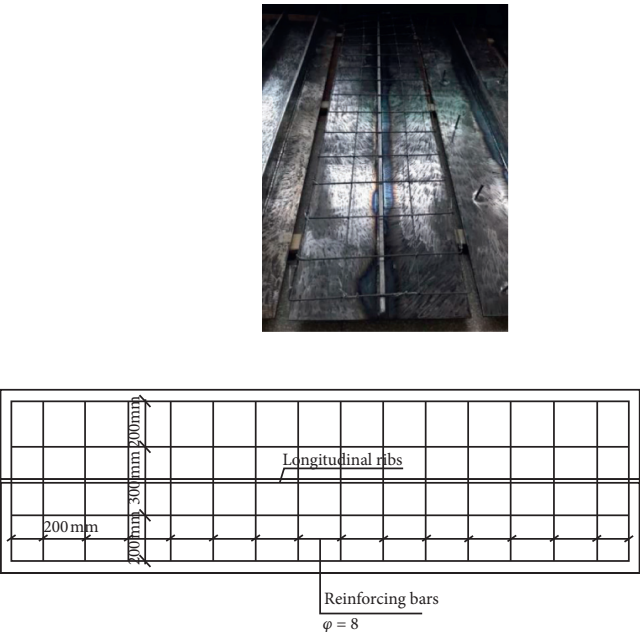

(c)

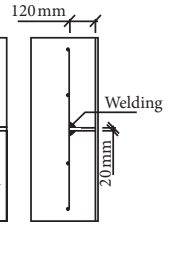

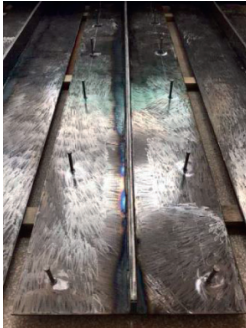

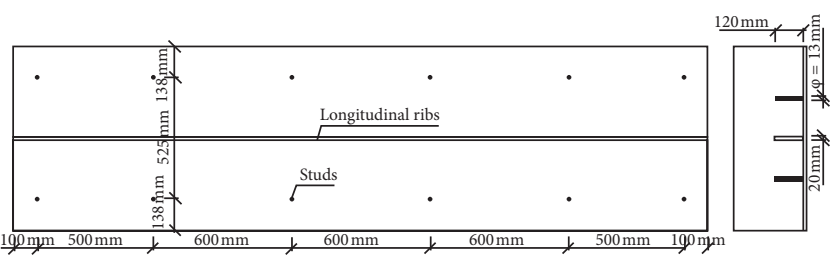

(b)
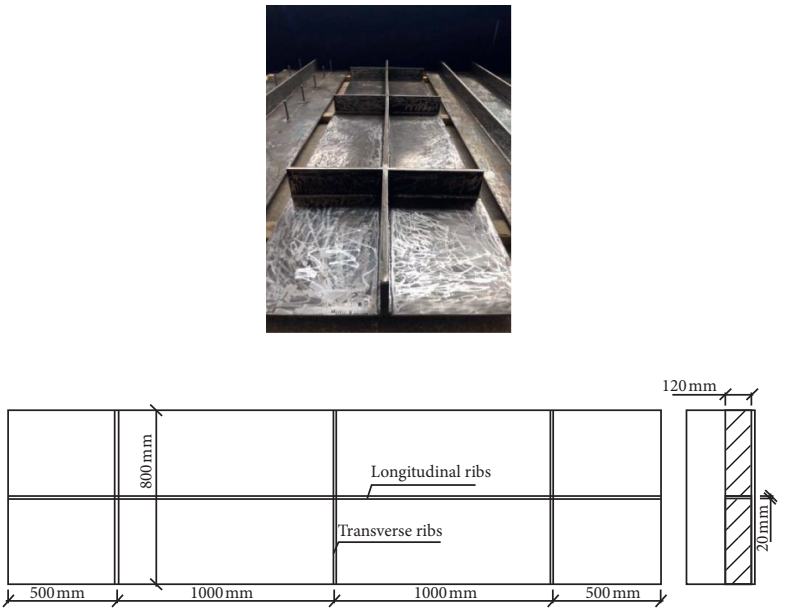

(d)

FIgURE 4: Continued. 

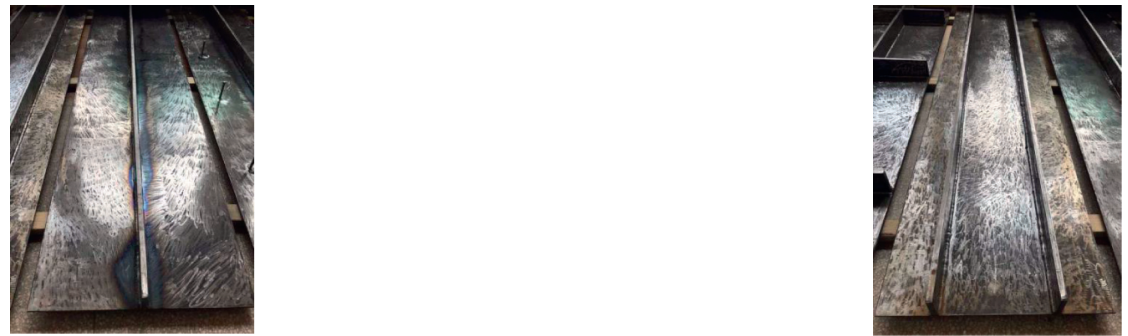

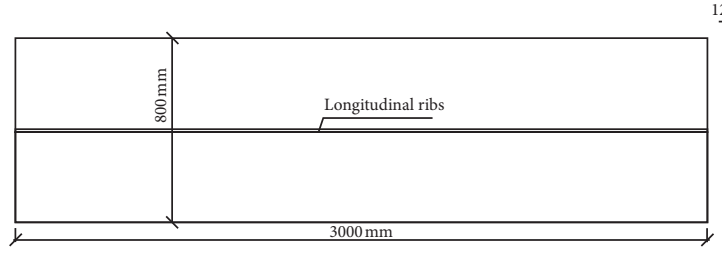

(e)

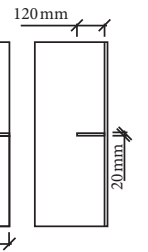

tr

\section{西}

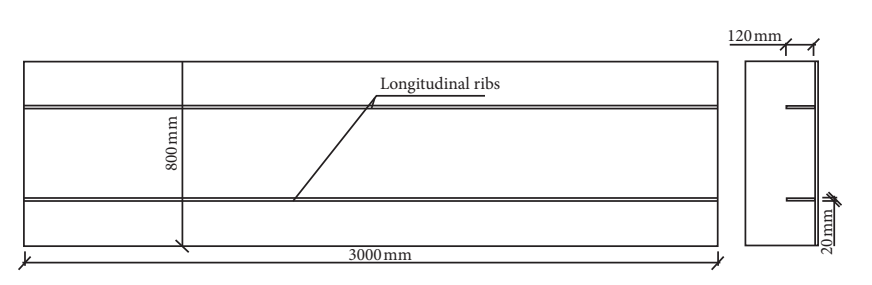

(f)

Figure 4: Photographs of the specimen: (a) SP1, (b) SP2, (c) SP3, (d) SP4, (e) SP5, and (f) SP6.

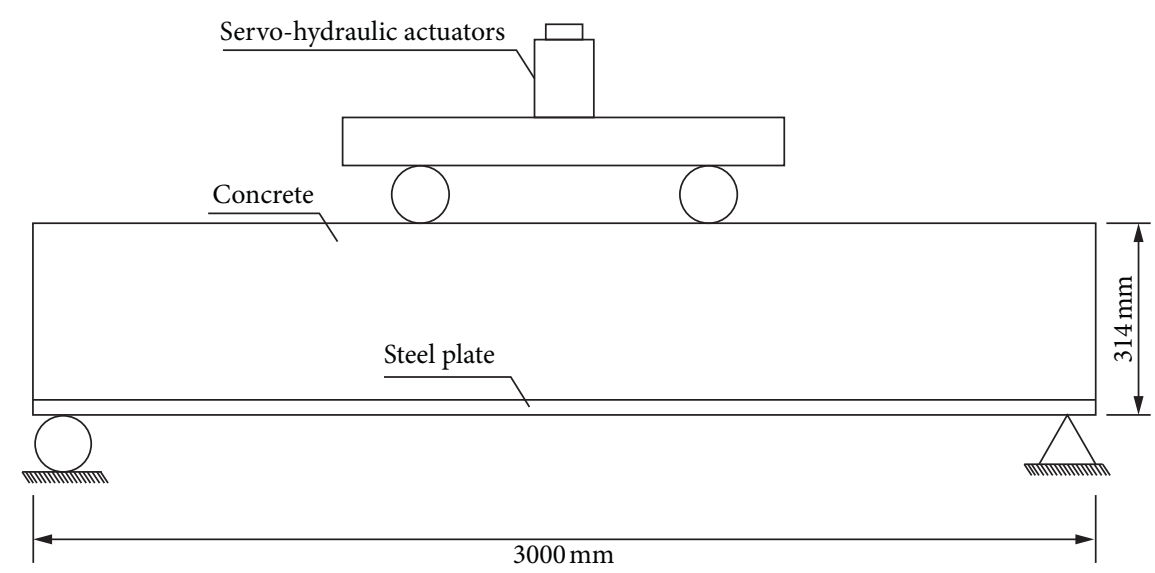

(a)

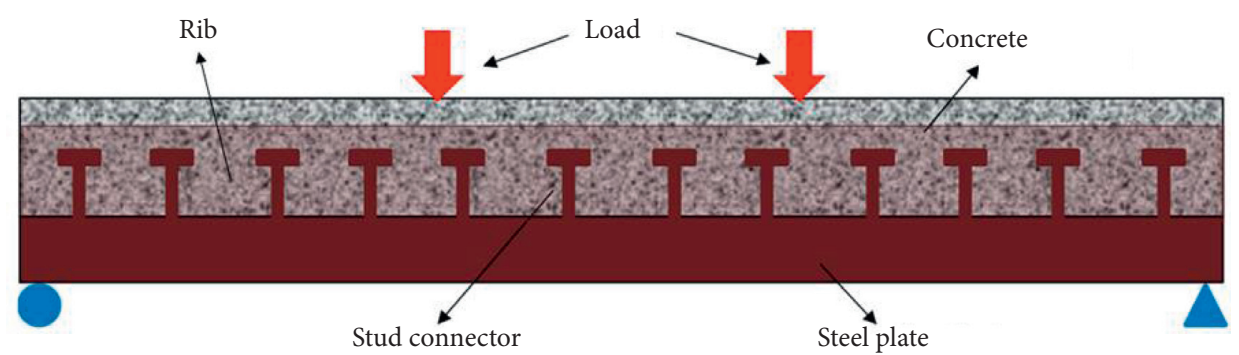

(b)

Figure 5: Test setup and instrumentation of specimens: (a) schematic diagram of test set-up and (b) general view.

relationship, slip curve and analysis of cycle times, and midspan deflection.

3.1. Failure Modes. The brittle failure of the six specimens is shown in Figure 7, and all specimens are eventually destroyed due to the penetration of concrete. Different shear connectors result in different ultimate bearing capacity and crack distribution of the specimen. The main crack distribution when the specimen fails is shown in Figure 8. The SP1 and SP2 use the stud connectors; the stud connector can better restrain the lateral displacement of the concrete. When the specimen is damaged, it will penetrate through the whole place under compression. The SP3 uses reinforcing bars-longitudinal ribs shear connectors, and the steel and concrete bear the pressure together. Although the ultimate bearing capacity of the test piece is increased, stress concentration is easy to occur at the welding place between the 


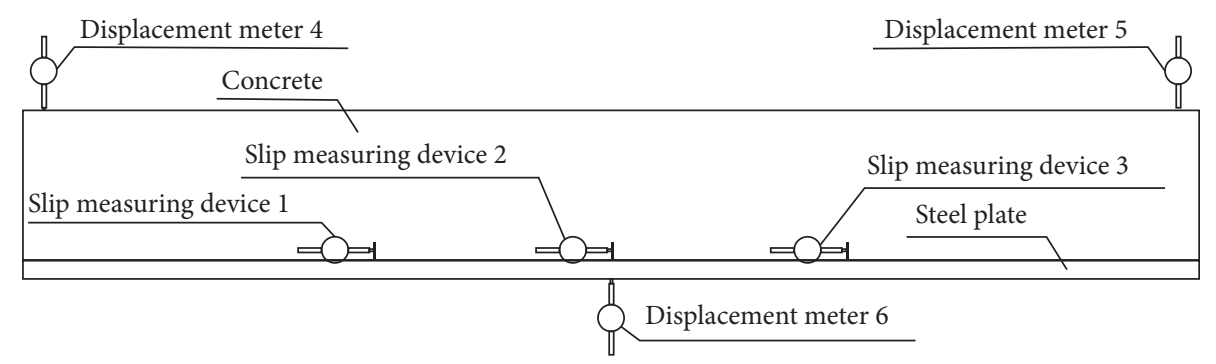

(a)

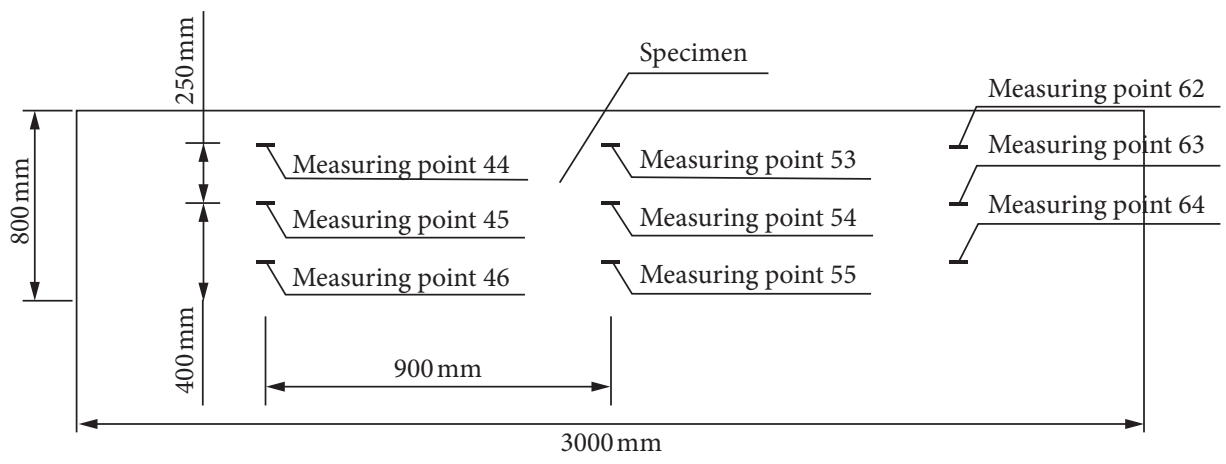

(b)

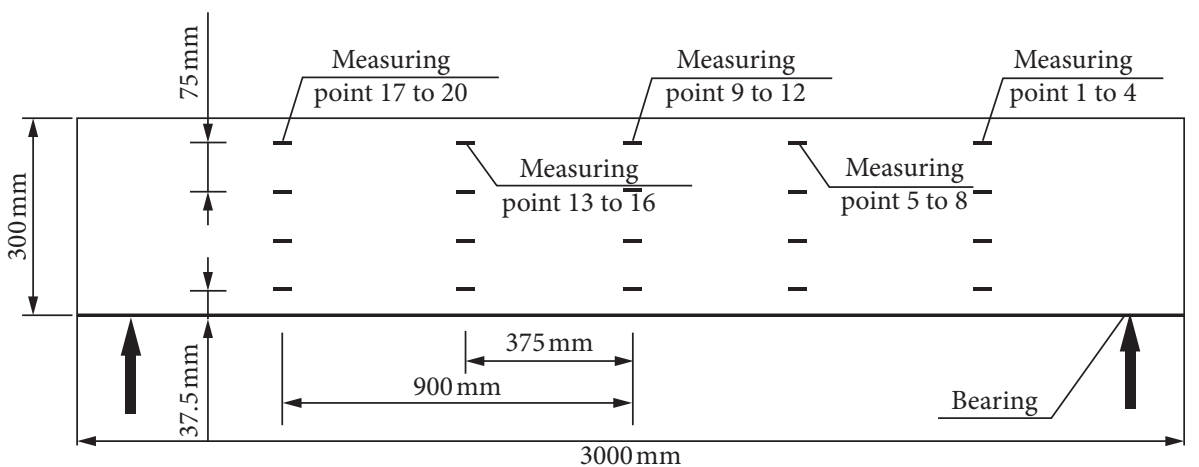

(c)

FIgURE 6: Point position map: (a) displacement meter layout, (b) arrangement of strain gauges, and (c) arrangement of strain gauges.

steel bar and the longitudinal ribs, and cracks are easily generated at this place and finally break through. The failure form of specimen 4 is obviously different from that of other specimens. Due to the presence of transverse rib connectors, as the load increases, the deflection of the specimen becomes larger and the squeezing effect of the transverse ribs on the concrete becomes more and more obvious; as a result, the specimen is prone to cracks at the transverse ribs. The crack distribution of SP1, SP5, and SP6 is basically the same. Compared with SP5, SP1 significantly improves the ultimate bearing capacity after using the studs connector, indicating the interface treatment of SP1 is excellent.

3.2. Mid-Span Load-Deflection Curve. The synergistic behavior of steel-self-compacting concrete beams under pure bending test and the deformation mechanism of composite members can be obtained by mid-span load-deflection curve.
The load-span deflection curves of the six specimens in the test are shown in Figure 9 and Table 5.

It can be seen from the test results that the ultimate bearing capacity of the SP1 and the SP4 is remarkably improved. According to the results, the ultimate bearing capacity of SP5 was only $256.2 \mathrm{kN}$; however, the ultimate bearing capacity of SP1 and SP4 was about $310 \mathrm{kN}$. Compared with the SP5, the ultimate bearing capacity of the specimen is increased by about $24 \%$.

The deformation properties of the composite members SP1 and SP4 under cyclic load are also significantly improved. The SP5 has passed from the elastic stage to the elastic-plastic stage at $200 \mathrm{kN}$, and the deflection becomes larger and the specimen is destroyed. During the loading process, SP1, SP4, and SP6 were in the elastic phase before the load reached $290 \mathrm{kN}$. The deflection increased linearly with the load and then entered the elastoplastic phase, and the load continued to increase. The specimen entered the plastic phase until the specimen was destroyed. The ultimate 


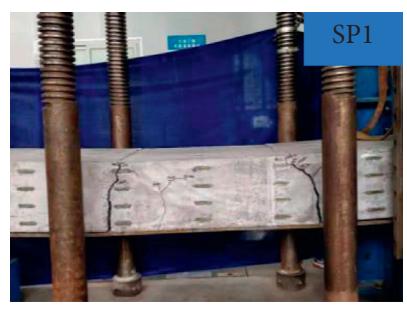

(a)

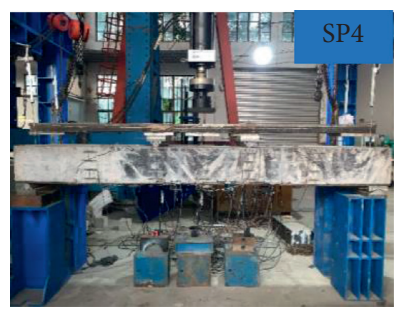

(d)

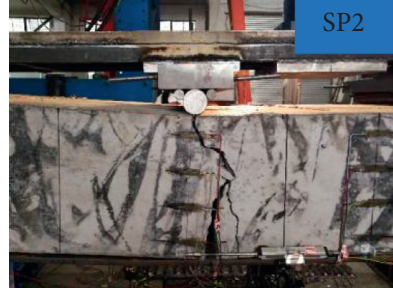

(b)

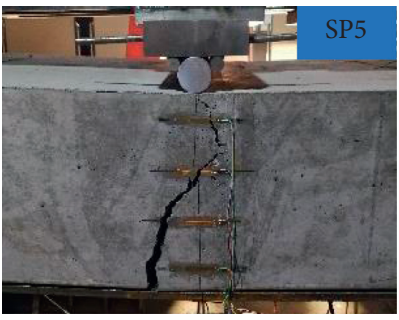

(e)

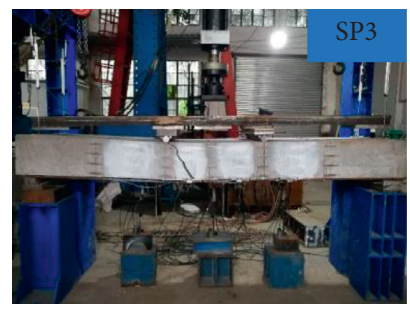

(c)

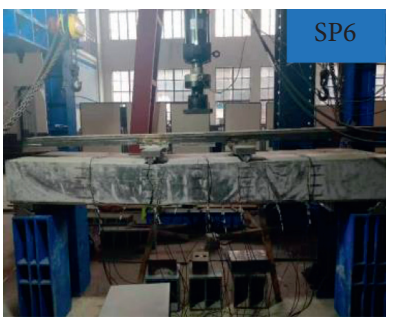

(f)

Figure 7: Brittle failure of specimens.

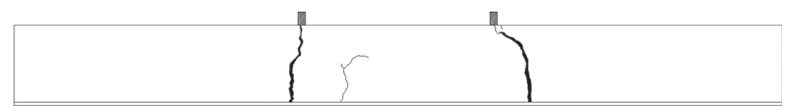

(a)

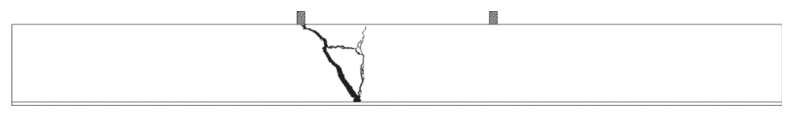

(c)

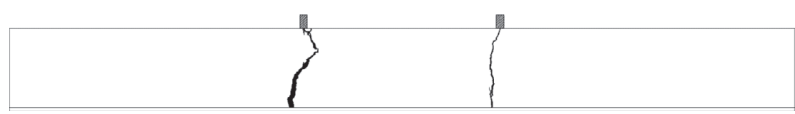

(e)

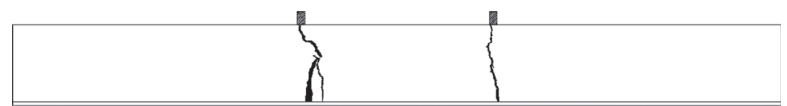

(b)

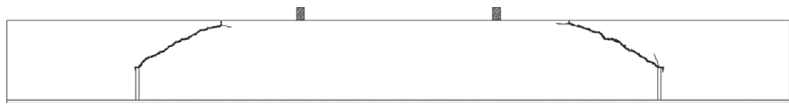

(d)

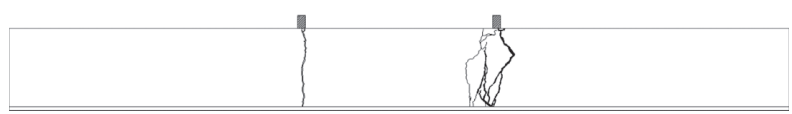

(f)

Figure 8: The main crack distribution of the specimen: (a) SP1, (b) SP2, (c) SP3, (d) SP4, (e) SP5, and (f) SP6.

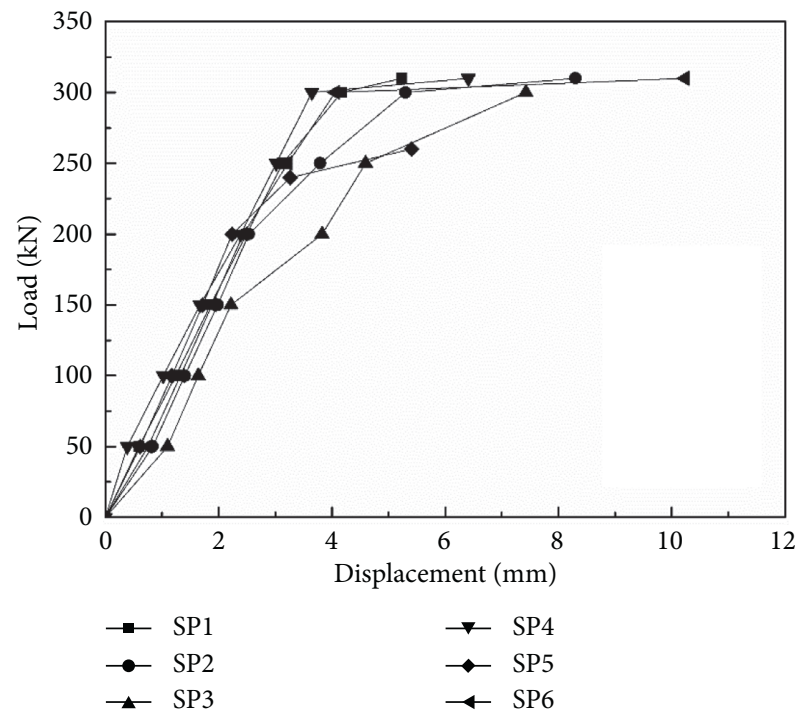

Figure 9: Specimen load-deflection curve.
TABle 5: Test results of specimens.

\begin{tabular}{lcccc}
\hline Specimen no. & $F_{u}^{1}(\mathrm{kN})$ & $F_{\mathrm{ud}}^{2}(\mathrm{~mm})$ & $F_{\mathrm{c}}^{3}(\mathrm{kN})$ & $F_{\mathrm{cd}}^{4}(\mathrm{kN})$ \\
\hline SP1 & 310.7 & 5.233 & 253.3 & 2.532 \\
SP2 & 305.6 & 6.632 & 241.7 & 2.322 \\
SP3 & 292.5 & 5.685 & 149.9 & 2.217 \\
SP4 & 308.5 & 6.743 & 205.9 & 2.469 \\
SP5 & 256.2 & 5.406 & 170.5 & 1.932 \\
SP6 & 299.1 & 4.914 & 250.0 & 3.274 \\
\hline
\end{tabular}

${ }^{1} F_{u}$ : ultimate bearing capacity of the specimens, ${ }^{2} F_{\text {ud }}$ : ultimate deformation of the specimens, ${ }^{3} F_{\mathrm{c}}$ : load value when the specimen is cracked, and ${ }^{4} F_{\mathrm{cd}}$ : deflection value when the specimen is cracked.

bearing capacity of SP2 and SP3 is high, but the elasticplastic stage enters the elastoplastic stage at about $200 \mathrm{kN}$, and its deflection changes greatly. In short, the ultimate load-bearing performance of SP1 and SP4 is the best.

3.3. Slip Curve. By observing the slip curve, the restraining effect of different shear connectors on the steel-concrete interface can be obtained. The slip curve of the six specimens is shown in Figure 10. 
For SP1, it can be seen from Figure 10(a) that the effect of the stud on limiting the lateral displacement of the concrete is very obvious. During the loading process of $0-280 \mathrm{kN}$, the displacement of the displacement gauges of No. 1 and No. 3 is only $0.2 \mathrm{~mm}$, and there is no huge mutation. Due to the damage of the displacement gauge No. 2, effective observation was not possible, and the data was not analyzed for the time being.

The slip curve of the SP2 is shown in Figure 10(b). During the whole cycle of $0-250 \mathrm{kN}$, the slip amount at the measuring points 1,2 , and 3 is almost 0 , and no crack is generated in the specimen. When the load is at the first cycle of $250 \mathrm{kN}$, the specimen produces tiny cracks at the measuring points 1 and 3 , and the slip points of the measuring points 1, 2, and 3 increase rapidly. Then the increment of the measuring point is almost constant at $0.01 \mathrm{~mm}$ until the load is increased to $300 \mathrm{kN}$, the crack continues to expand, the slip further increases in a smooth curve, the specimen enters the plastic stage, and then the slip increases by $1 \mathrm{~mm}$, and the specimen is destroyed.

The slip curve of SP3 is shown in Figure 10(c). The displacement of the whole slip curve is small before the specimen is destroyed. There is a sudden change at $170 \mathrm{kN}$, and the crack appears on the concrete surface of the specimen. Eventually, the displacement gauge No. 1 changed $1.17 \mathrm{~mm}$ and fell off at $300 \mathrm{kN}$. The displacement gauge No. 2 changed by $0.103 \mathrm{~mm}$, and the displacement gauge No. 3 finally changed by $1.051 \mathrm{~mm}$.

The slip curve of SP4 is shown in Figure 10(d). Before $250 \mathrm{kN}$, the slip of the specimen was only $0.1 \mathrm{~mm}$, and when the load was increased to $300 \mathrm{kN}$, the slip curve did not show a huge mutation. The whole increment was $0.2 \mathrm{~mm}$, indicating that the longitudinal ribs and transverse ribs of the steel plate well limit the displacement of the concrete, and the synergistic force performance is good, and the good bearing performance can be maintained when the bearing capacity is increased.

The slip curves of SP5 are shown in Figure 10(e). There is no sudden change in the slip values of test points 1 and 2 before the failure of the specimen. The change of test point 3 at $170 \mathrm{kN}$ is due to the local failure at that point and the enlargement of concrete cracks. When the load is $250 \mathrm{kN}$, the specimen is destroyed and the displacement meter is invalid.

The slip increment of the SP6 before complete damage is about $0.01 \mathrm{~mm}$, which indicates that the concrete and the steel plate have good combined force, which can effectively limit the lateral displacement of the concrete. When the load is $230 \mathrm{kN}$, the slip gradually increases, and the specimen starts partially. Cracks occurred until the load became $300 \mathrm{kN}$, and the slip suddenly became large, and the specimen broke, as shown in Figure 10(f).

According to the slip curve, SP3 and SP6 had the worst performance and the worst constraint effect on the lateral displacement of concrete. SP1, SP4, and SP5 showed outstanding performance, and the lateral displacement always changed in a small range, among which SP1 and SP5 had the smallest fluctuation in the process of change.
3.4. Analysis of Cycle Times and Mid-Span Deflection. In order to further study the influence of the pressurization and unloading process on the specimen during the cycle, the development of the deflection of the six specimens with the increase of the number of cycles is obtained, as shown in Figure 11. It can be seen from the test results that the SP1 and the SP 4 are least affected by the number of load cycles. During the application of the reciprocating load, the deflection of the SP1 and the SP4 is in a linear increase process until the specimen is broken. The SP 5 was most affected by the number of cycles, and at the 20th cycle load, the deflection of the SP5 was abrupt and then rapidly destroyed. In the process of cyclic pressure, the SP3 has the weakest stability, and the deflection has become significantly larger at the 15 th cycle. Therefore, in the case of repeated loading and unloading, the interface processing method of SP1 and SP4 is the best.

3.5. Load-Strain Relationship. The development law of the mid-strain strain with load of the six specimens is shown in Figure 12. Among them, the SP1 failed to make effective observation due to the damage of the strain gauge at the measuring point 7 , and the data was not analyzed.

It can be seen from the test results that the strains of the SP1, SP2, and SP5 are in accordance with the development law, and the concrete and the steel plate have better combined force performance. Among them, SP1 and SP2 did not appear to suddenly increase the strain of the specimen but showed the property of first elastic and then elastoplastic change. As the load of SP3, SP5, and SP6 increases, the strain at a certain measuring point suddenly increases, and the crack in the specimen causes the joint to be broken, and the force on the steel plate suddenly increases.

The load-strain curves of the steel plates at the bottom of SP1, SP4, and SP5 are shown in Figure 13. The test results show that the specimen has the best synergistic force when the longitudinal rib and the stud are used as the connecting piece. As shown in Figure 13(a), the load-strain curve increases linearly, and the whole specimen is in the elastic stage before $290 \mathrm{kN}$. When the specimen is used as the connecting member with the longitudinal rib and the transverse rib as the connecting member, the effect is slightly worse than that of the SP1, and the whole of the specimen enters the elastoplastic stage too early. When the specimen is only used as the connecting piece with the longitudinal rib, the synergistic force performance is poor, the force transmitted to the steel plate after the concrete cracking increases, and the restraining effect of the longitudinal rib on the concrete is poor.

Figure 14 is the height-strain curve of the SP2. It can be seen that the cross section strain of the test beam varies linearly along the height direction, and the assumption of flat cross section is valid. In addition, the position of the neutral layer of the test beam gradually moves down during the loading process. The main reason is that the steel plate acts synergistically in the lower layer of the specimen, and the stress change is smaller than that in the upper layer, which results in the noncoincidence of the strain neutral layer and the geometric neutral layer, and the strain neutral layer moves downward. 


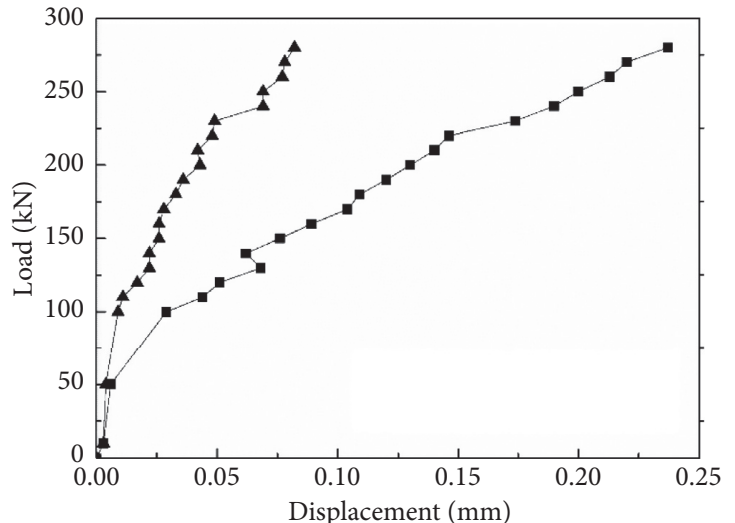

$\rightarrow \quad$ Displacement meter 1

ـ Displacement meter 3

(a)

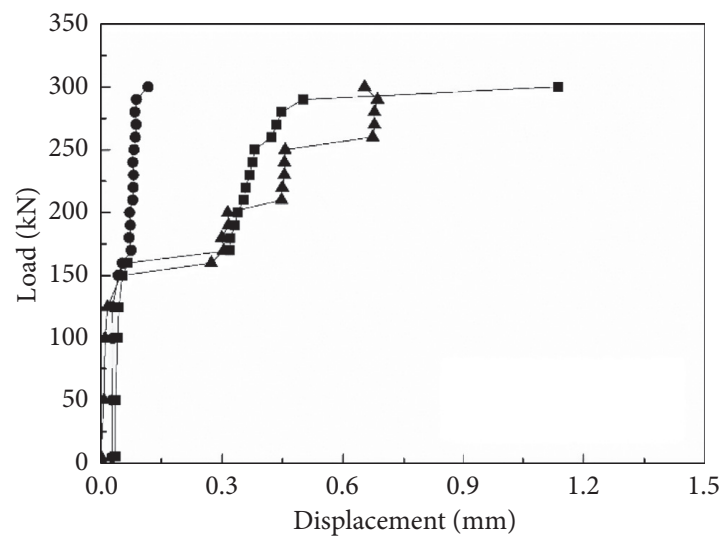

- Displacement meter 1

- Displacement meter 2

๘ Displacement meter 3

(c)

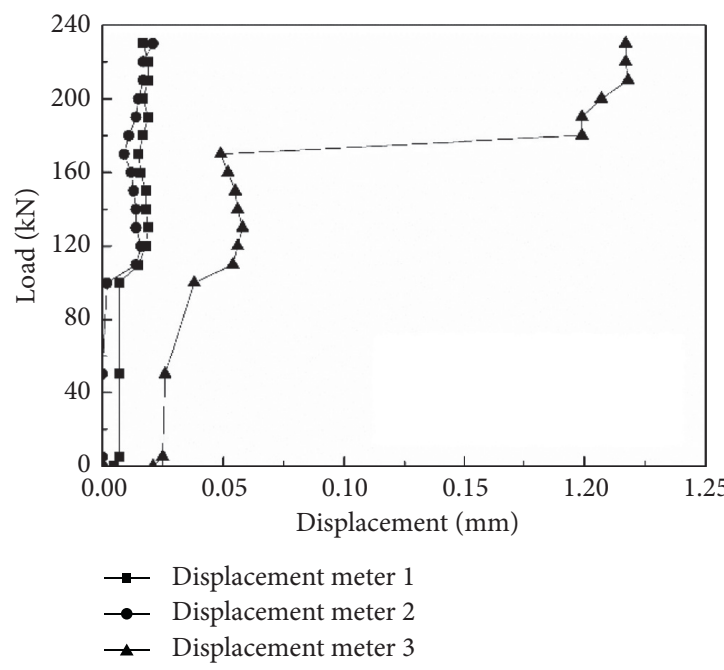

(e)

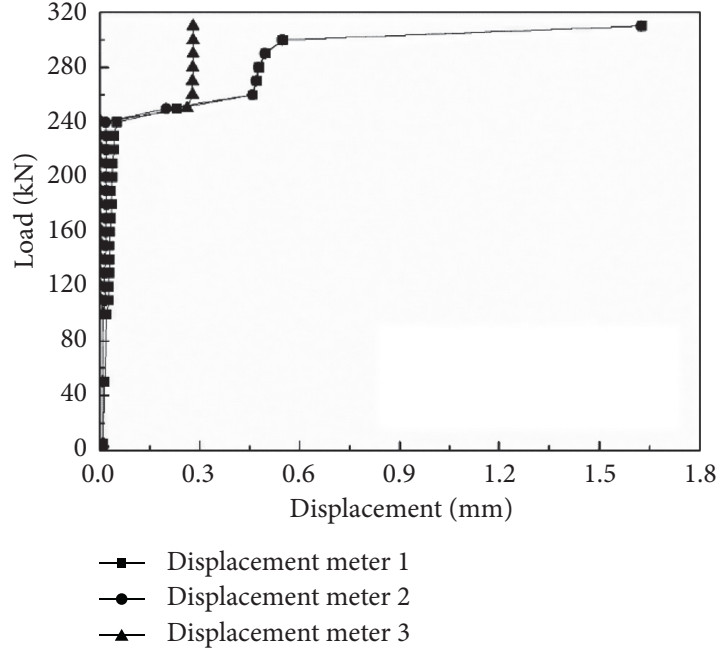

(b)

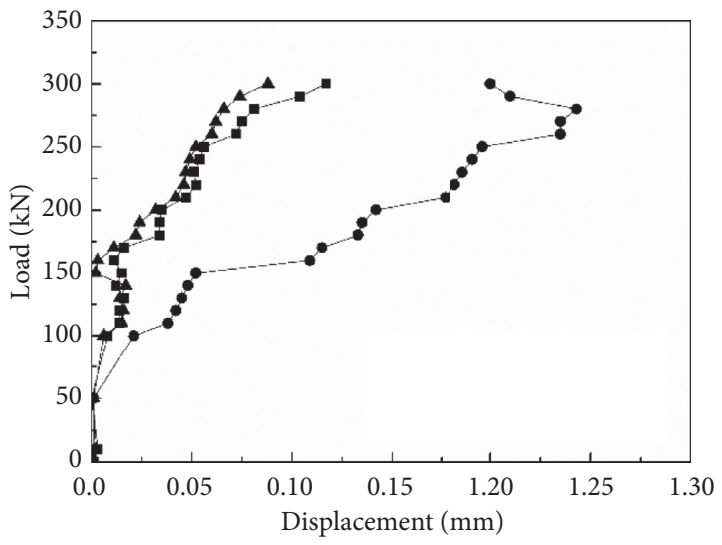

$\rightarrow \quad$ Displacement meter 1

$\rightarrow$ Displacement meter 2

$\leftarrow$ Displacement meter 3

(d)

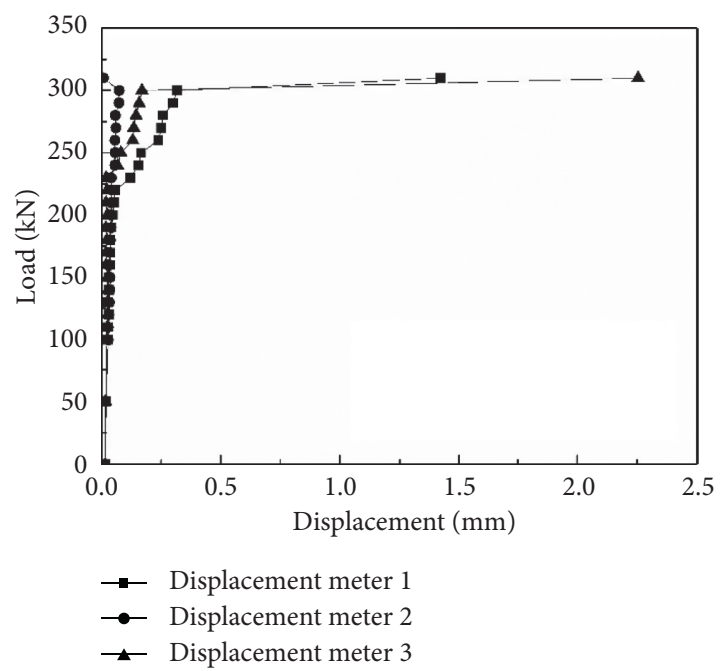

(f)

Figure 10: Slip curves: (a) SP1, (b) SP2, (c) SP3, (d) SP4, (e) SP5, and (f) SP6. 


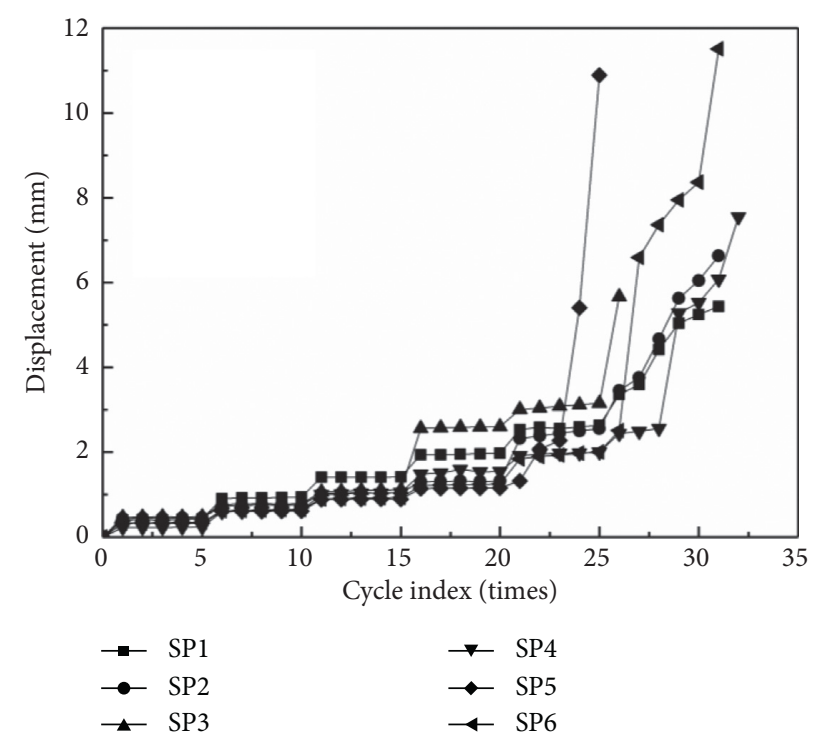

Figure 11: Cycle times and mid-span deflection curve.
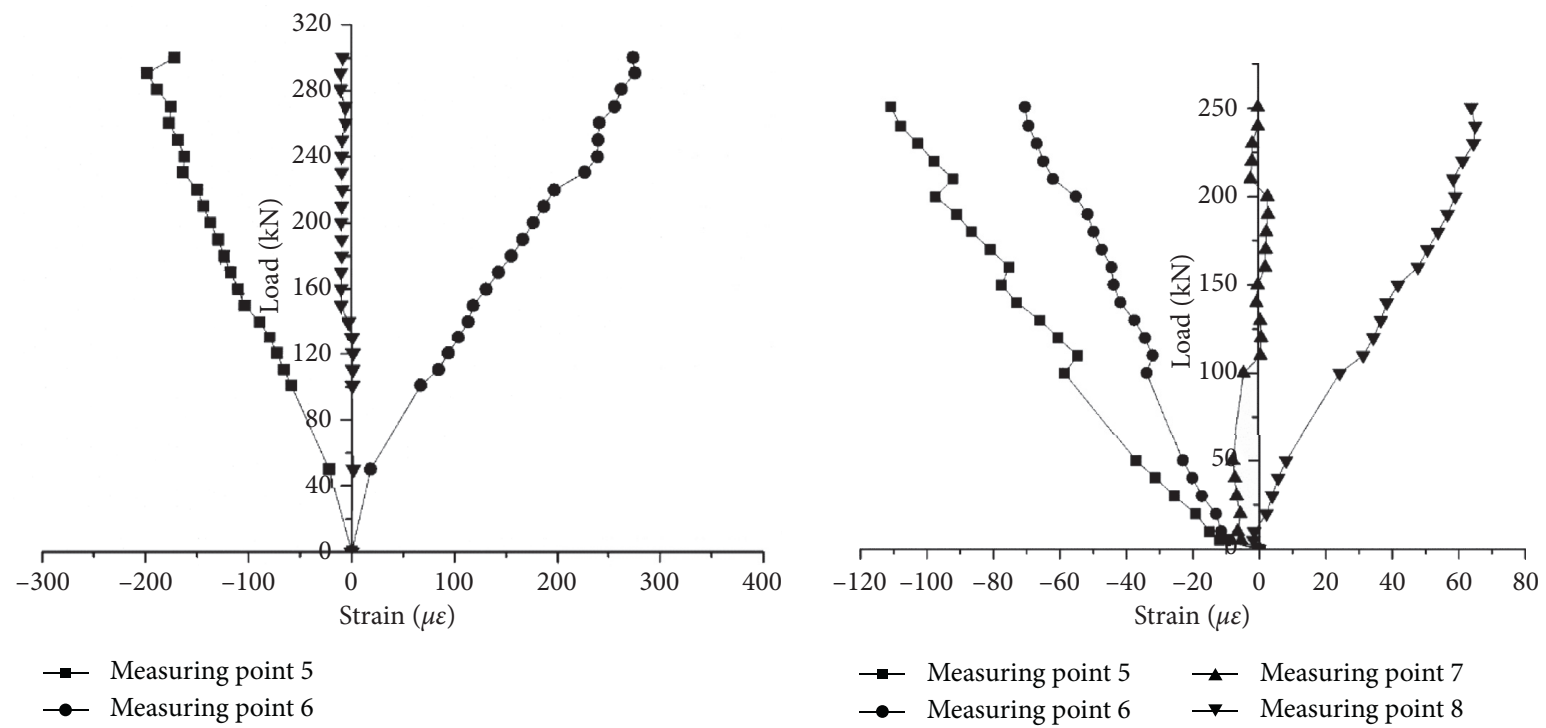

(a)

(b)

Figure 12: Continued. 


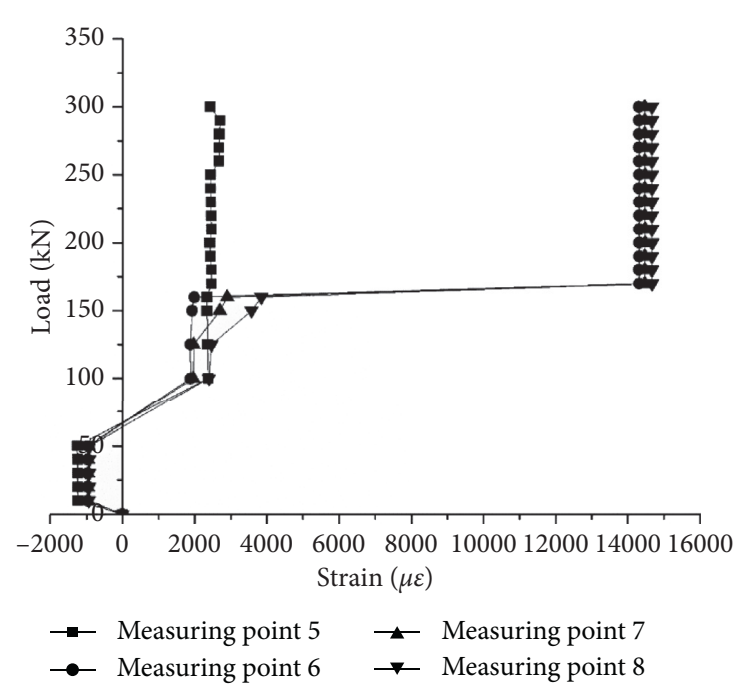

(c)

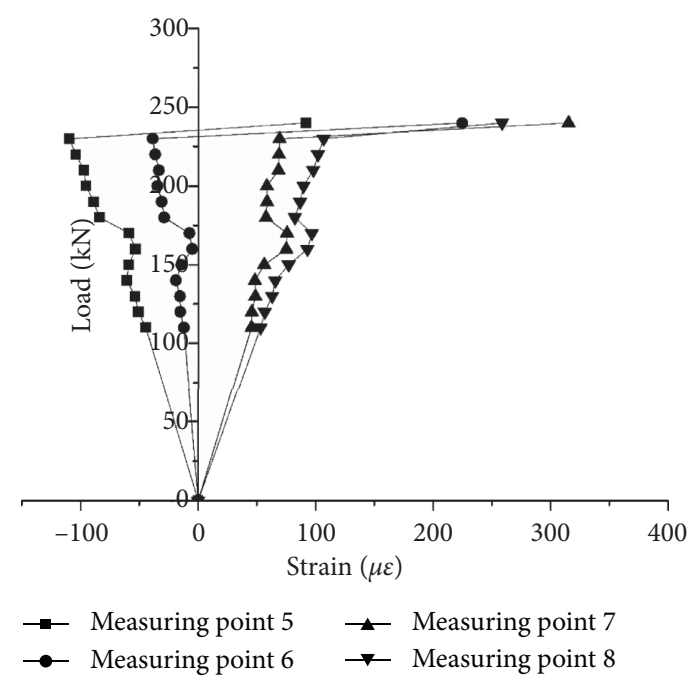

(e)

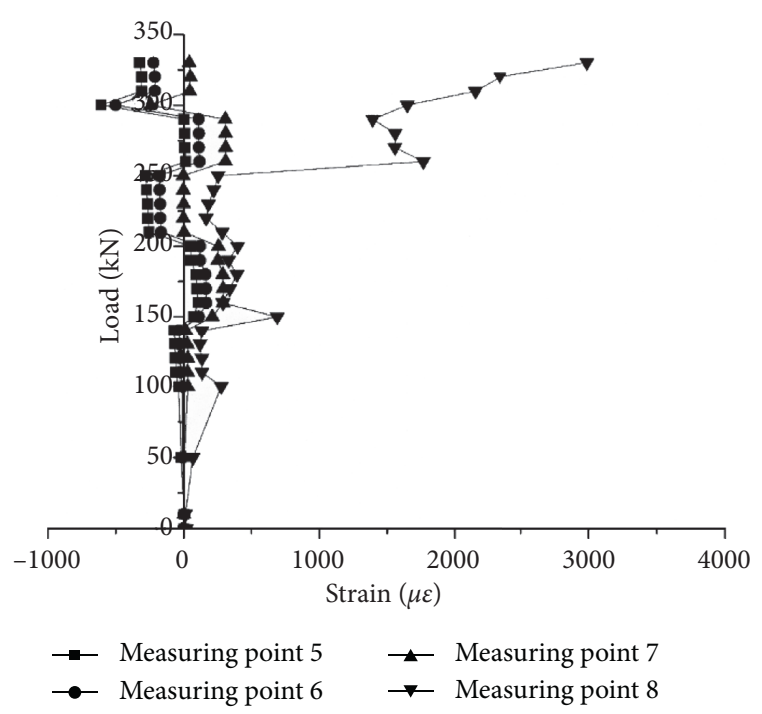

(d)

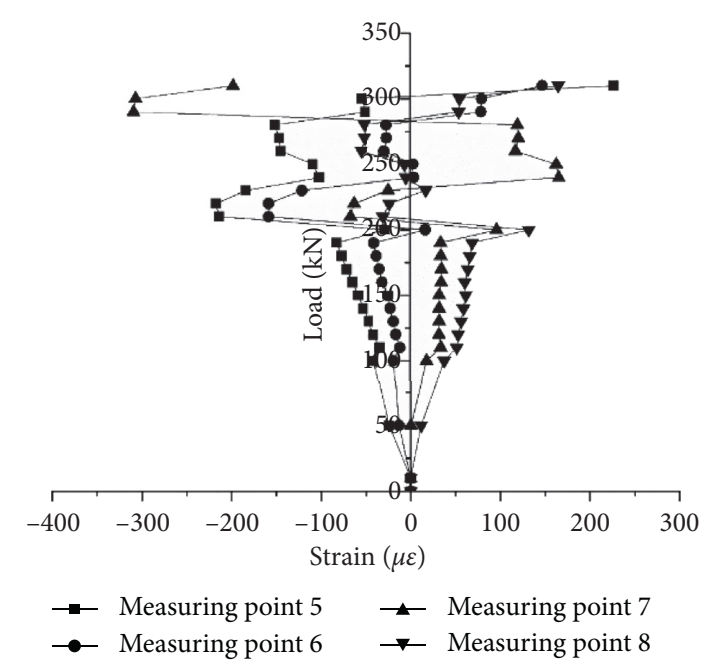

(f)

FIGURE 12: Strain-load curves for each measuring point on the side of the specimens: (a) SP1, (b) SP2, (c) SP3, (d) SP4, (e) SP5, and (f) SP6.

\section{Finite Element Analysis (FEA) Model}

4.1. Analysis of the Load Transfer Mechanism in Interface. The bearing capacity of the studs and ribs shear connectors were affected by the material properties of concrete, the material properties of the studs and ribs shear connectors, and the bond properties of the interface. Among them, the interaction between shear connectors and concrete in spatial scale determines the mechanism of load distribution and the distribution characteristics of concrete damage and then affects the bearing capacity of the two materials, respectively. Therefore, based on force mechanism analysis, the shear connectors and concrete under the three-dimensional scale of relative motion are decomposed; the interaction of shear connectors and concrete separately for the equivalent of two kinds of materials to the interface method of mutual extrusion, toroidal at the interface between the mutual friction and reinforcing rib protrusions and concrete local extrusion, the load transfer mechanism of the corresponding description and quantitative calculation method was proposed to characterize the damage effect of concrete influence on bearing performance, thus establishing the stud three-dimensional constitutive relationship of concrete interface model, as shown in Figure 15. Then, by studying the distribution characteristics of concrete damage along the axial direction of studs, the compression strain of concrete is chosen as the quantitative index to characterize the damage degree of concrete, and a quantitative calculation method is proposed to consider the coupling effect of axial bonding damage and local compression damage on the interface load transfer performance. Based on the experimental results, the correlation index in the model is calibrated, and then the spatial three-dimensional stress field of the steel-concrete interface model is constructed, which provides a numerical analysis tool for the study of the mechanical properties of the steel-concrete interface. 


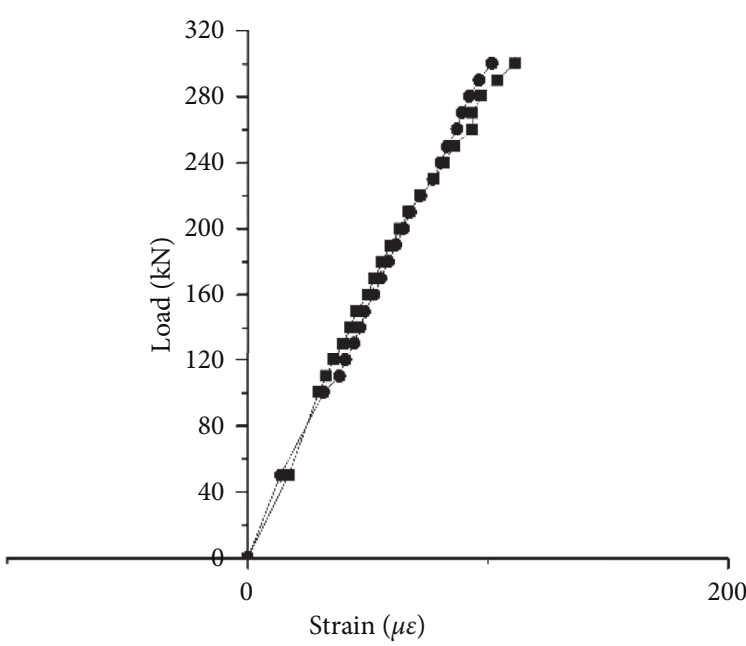

$\rightarrow$ Measuring point 54

$\multimap$ Measuring point 55

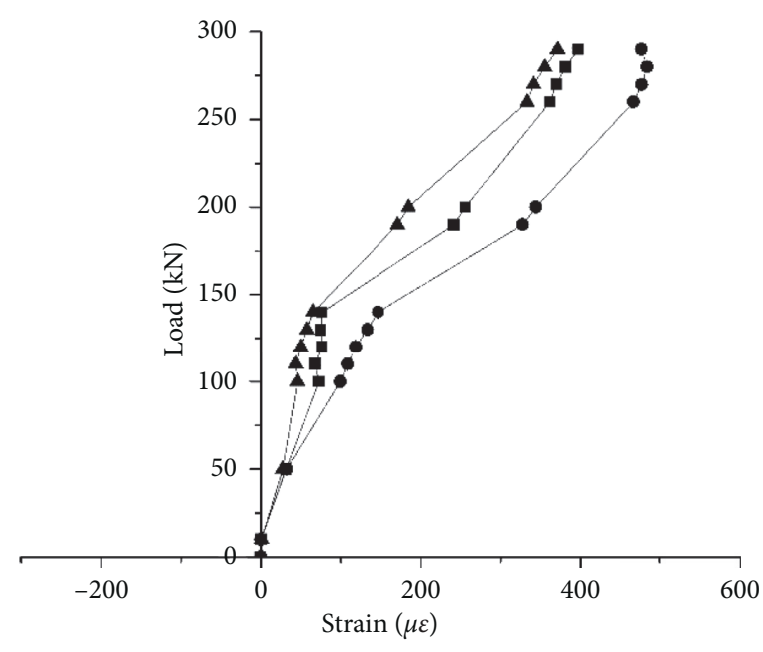

$\rightarrow-$ Measuring point 53

- Measuring point 54

$₫$ Measuring point 55

(b)

(a)

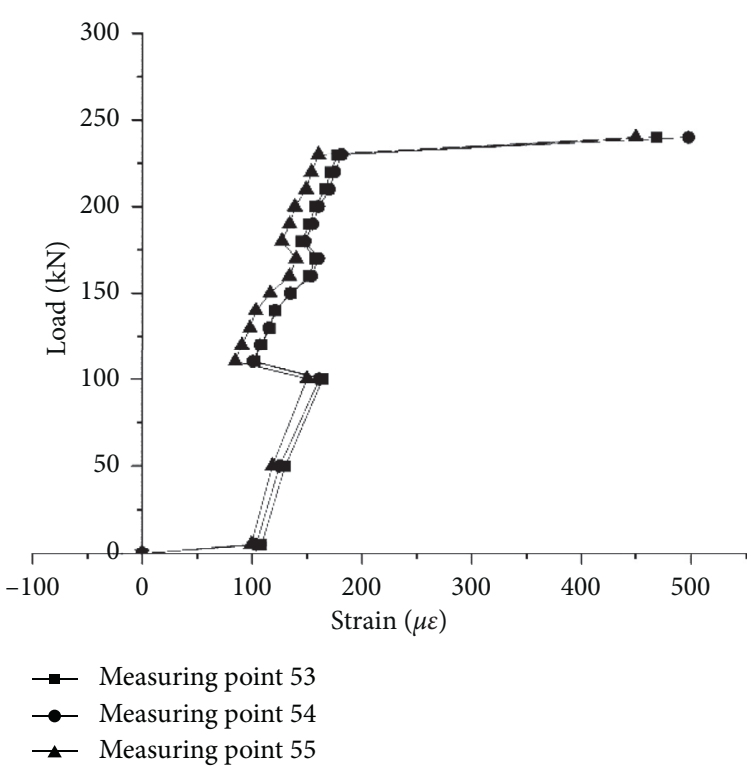

(c)

FIgURE 13: Strain-load curves for each measuring point at the bottom of the specimens: (a) SP1, (b) SP4, and (c) SP5.

Through the above methods, the relative motion of concrete and stud shear connectors in the spatial coordinate system is decomposed, and the corresponding load transfer mechanism is determined in the three directions of interface normal, interface ring, and stud axis, respectively. When the composite member is under load pressure or tension, the normal stress between the concrete and the contact surface of the stud is equivalent to the mutual extrusion between the stud and the concrete. The annular displacement of the interface is equivalent to the friction between the stud and the concrete. The axial failure of the stud is regarded as the local extrusion between the stud and the concrete. Assuming that the circumferential friction along the interface of the model meets the molar coulomb criterion, the circumferential stress and the normal stress can be calculated according to (1) and (2), respectively, as shown in Figure 16:

$$
\begin{gathered}
\left\{\begin{array}{c}
\mathrm{d} \tau_{n}=G_{n} \mathrm{~d} \delta_{1}, \\
\int_{\text {path }} \mathrm{d} \tau_{n} \leq \mu \sigma_{n},
\end{array}\right. \\
E_{n} \omega, \omega<0, \\
0, \omega \geq 0,
\end{gathered}
$$

where $\tau_{n}$ is the axial friction stress, $\sigma_{n}$ is the normal stress, $\mu$ is the sliding friction coefficient between steel and concrete, and $G_{n}$ is the axial friction stiffness. 


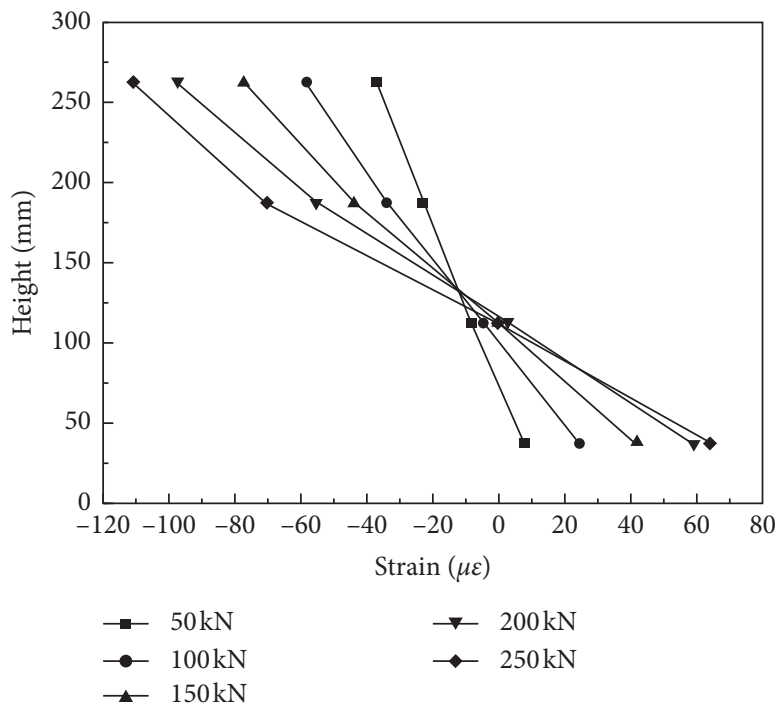

FIgURE 14: Section height-strain curve.

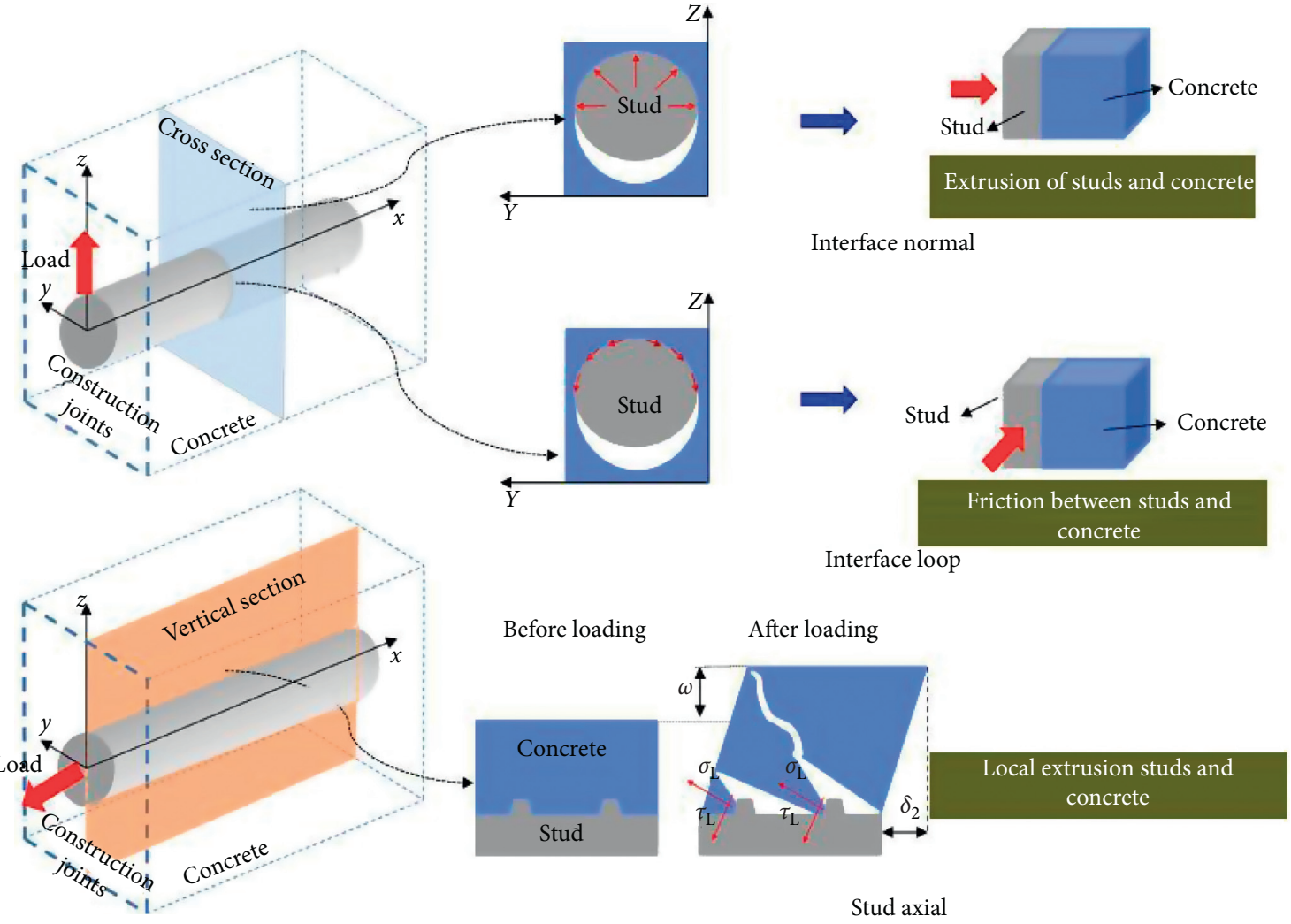

FIgURE 15: Three-dimensional relative motion decomposition and load transfer of interface.

Additionally, $G_{n}$ and $E_{n}$ are calculated as follows:

$$
\begin{aligned}
& G_{n}=0.5 E_{n}, \\
& E_{n}=343 f_{c}^{1 / 3},
\end{aligned}
$$

where $f_{c}$ is the compressive strength of concrete.
4.2. Verification of FEA Model. In this paper, the nonlinear analysis software Link3D developed by Maekawa [23] in Japan was used to simulate the test of steel-concrete composite members. The FEM of the composite structure is shown in Figure 17. The model was built according to the actual size of the specimen. In order to better simulate the real test situation, the loading point and the constraint point were all at the element node. The ratio of model elements in 


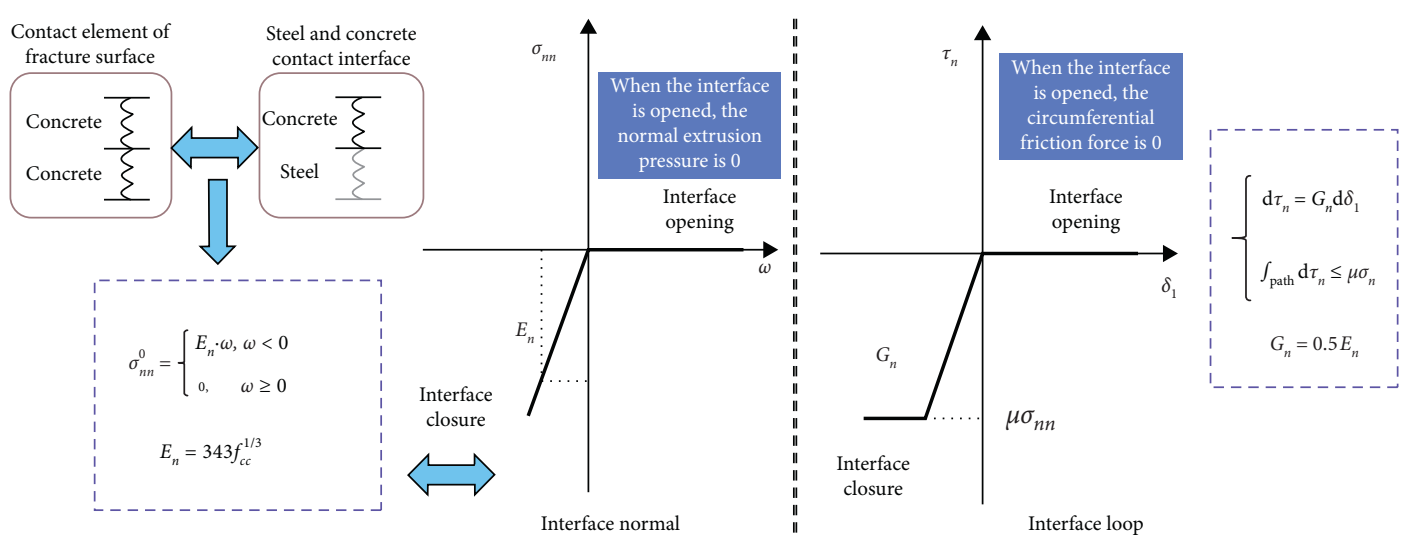

Figure 16: Quantitative expression.

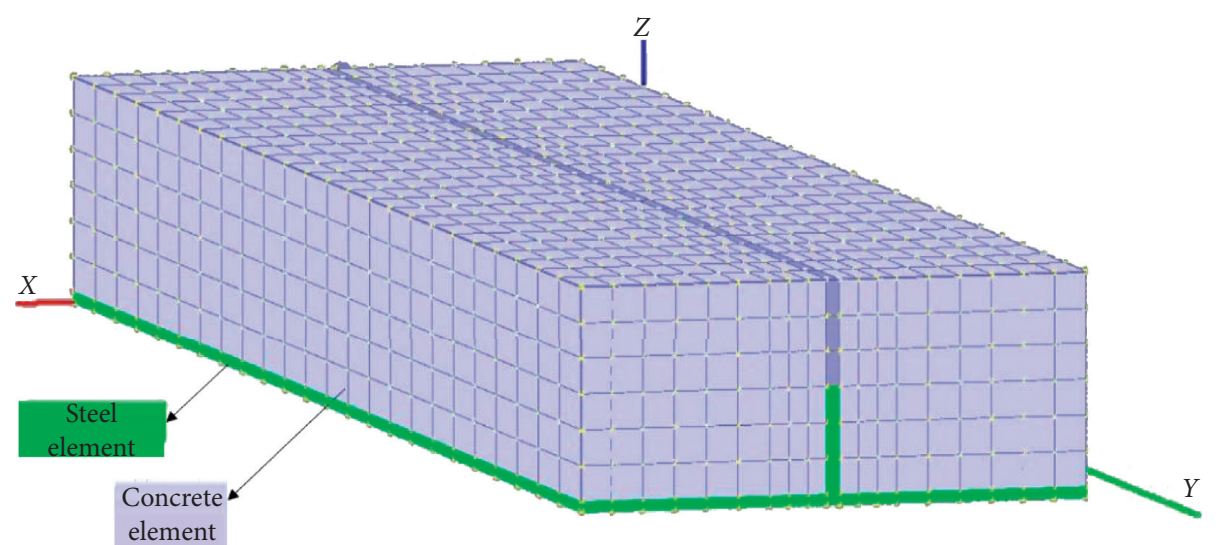

Figure 17: FEM simulation model.

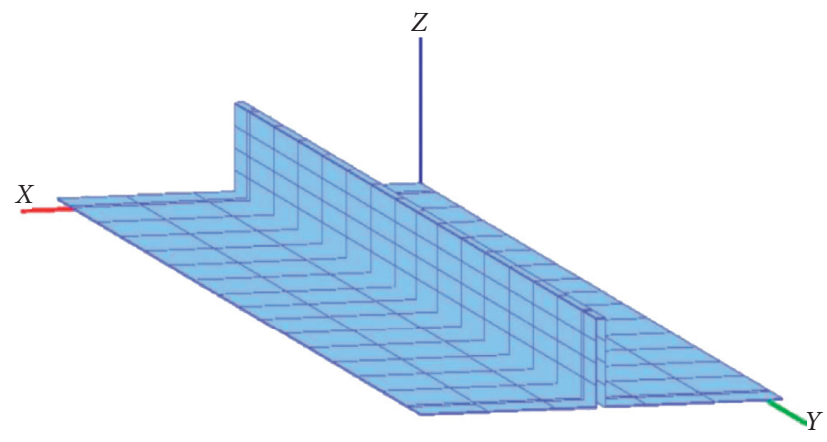

FIGURE 18: Bond element.

the $x$-direction is $150: 40: 20: 100: 90: 90: 100: 20: 40: 150$, the ratio of model elements in the $y$-direction is $100: 25$ : $200: 200: 200: 200: 200: 200: 175: 175: 200: 200: 200: 200$ : $200: 200: 25: 100$, and the thickness of the steel plate in the $z$-direction is $1.4 \mathrm{~cm}$; the height of the concrete element is $30 \mathrm{~cm}$ and it is divided into 10 parts on average and a total of 1980 elements were established. The load step setting is consistent with the test load. If we consider the initial imperfections, we need to set imperfections in the model before being subjected to the load, and we will consider these factors in future research.

In addition, considering the interaction between concrete and steel plate, a bond element is set at the surface between concrete and steel plate. The bond element is shown in Figure 18, and the material properties of the bond element are set according to Table 6 . The material properties of concrete element and steel plate element are shown in Figure 19. 
TABLE 6: Material properties of the bond element.

\begin{tabular}{lcccc}
\hline $\begin{array}{l}\text { Shear stiffness in closure } \\
\text { mode }\left(\mathrm{kgf} / \mathrm{cm}^{3}\right)\end{array}$ & $\begin{array}{c}\text { Normal stiffness in closure } \\
\text { mode }\left(\mathrm{kgf} / \mathrm{cm}^{3}\right)\end{array}$ & $\begin{array}{c}\text { Frictional } \\
\text { coefficient }\end{array}$ & $\begin{array}{c}\text { Shear stiffness in open mode } \\
\left(\mathrm{kgf} / \mathrm{cm}^{3}\right)\end{array}$ & $\begin{array}{c}\text { Normal stiffness in } \\
\text { open mode }\left(\mathrm{kgf} / \mathrm{cm}^{3}\right)\end{array}$ \\
\hline 10000 & 1000000 & 0.5 & 100 & 10 \\
\hline
\end{tabular}

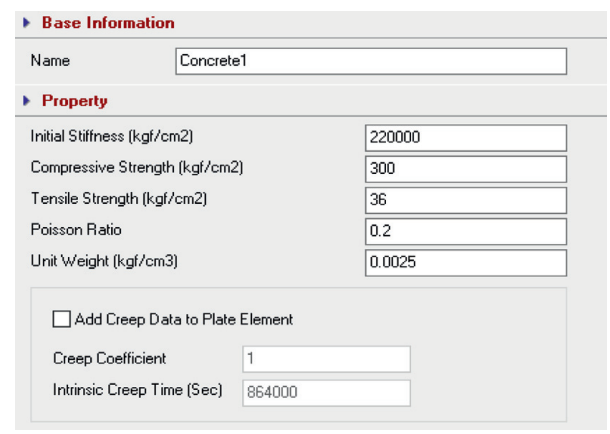

(a)

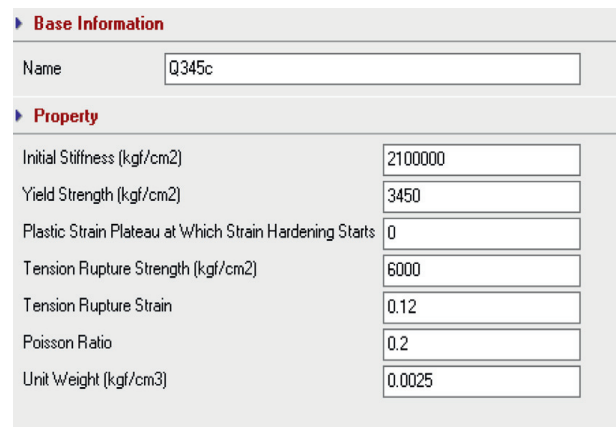

(b)

Figure 19: Material properties of the model: (a) material properties of the concrete element and (b) material properties of the steel plate element.

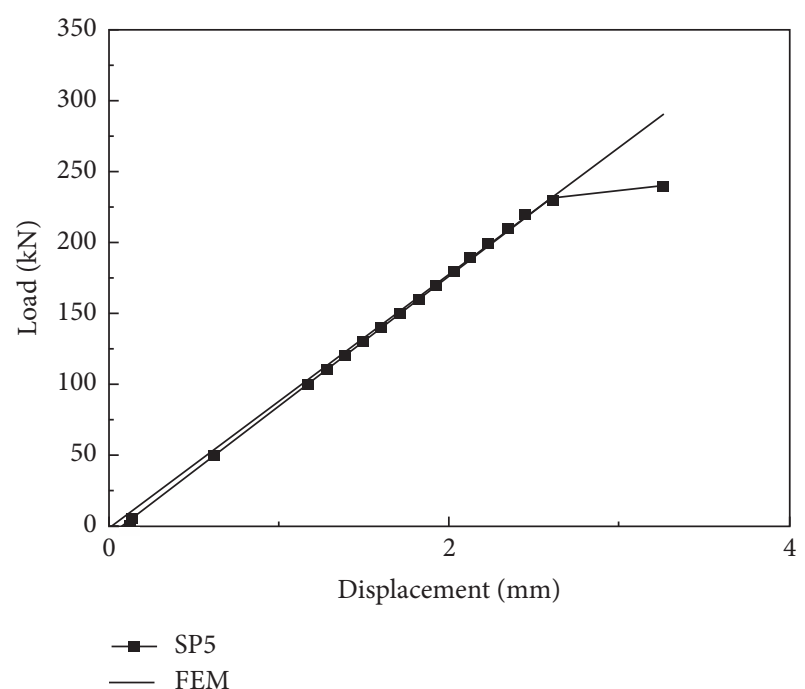

Figure 20: Comparison of load-deflection curve between simplified model and test results.

To verify the validity of the FEM model, load-deflection curve by the above-mentioned FEM model was compared with the tested results in this paper, as shown in Figure 20.

It can be seen from the simulation results that the numerical results obtained by the simulation method in this paper are slightly larger than the experimental results. However, the deviation is small, which can reflect the failure of steel-self compacting concrete composite members more accurately. The applicability of the model is verified, which has an important reference value for the study of similar tests and the prediction of mechanical properties of steel selfcompacting concrete composite members.

\section{Conclusions}

The behavior of steel self-compacting concrete beams has been studied under cyclic loads. And the finite element model is developed. Further research is also still needed on steel self-compacting concrete beams that are used in the field. From the range of the test parameters studied in this paper, the following conclusions can be drawn based on the above results:

(1) Under the early low load, the steel and concrete meet the plane section assumption, and the interaction between them is not obvious. After the load is gradually increased to a certain degree, the concrete will be under pressure and generate microcracks at the interface. The load will be transferred to the steel plate through the shear connector. At this time, the constraint effect of the shear connector on the concrete becomes obvious. The setting of shear connectors can greatly enhance the ultimate bearing capacity of steel-concrete composite structures, in which the ultimate bearing capacity of composite members composed of studs-ribbed shear connectors is increased by about $24 \%$ compared with that of composite members composed of only longitudinal ribbed shear connectors. In such projects, the interface processing method of SP1 is the most reasonable.

(2) From the slip curve, the steel self-compacting concrete beam with the stud or the transverse rib as the connecting piece can be seen; during the whole loading process, there is no obvious relative slip phenomenon. The concrete and steel plate always work together, and the overall bearing capacity is 
good. The restraining effect is the best, and the slip does not change.

(3) The stud-longitudinal rib shear connectors and transverse rib-longitudinal rib shear connectors perform best under the cyclic load. When the SP1 is broken, the crack is concentrated at the compression axis, and when the SP4 is broken, the crack is concentrated at the transverse rib. When the transverse ribs are used as shear connector, the cracks produced by the specimen under stress tend to expand diagonally, which is more prone to shear failure. When considering slippage, SP1 and SP4 interface treatment method is the most reasonable, but the crack of SP4 is easy to occur at the shear connector, and the SP1 interface treatment method is the best choice.

(4) As a new material, the compressive strength of selfcompacting concrete can meet the compressive strength requirements of ordinary concrete. It has higher applicability for large-scale construction site and complex underground construction, and the test has a higher reference significance for future engineering application.

(5) Based on the finite element modeling theory, the steel-concrete coupling frame with interface load transfer mechanism is analyzed, and the steel-self compacting model was established. The finite element software Link3D is used to simulate the tests of composite components. By comparing the test results with the simulation results, the deviation of the results is small. The model has a certain reference value for similar tests in the future and has an important significance in predicting the mechanical properties of steel-self compacting concrete.

\section{Data Availability}

The test data are included within the article and can be made freely available.

\section{Conflicts of Interest}

The authors declare that there are no conflicts of interest regarding the publication of this manuscript.

\section{Acknowledgments}

This research was funded by the Research Program of the Pearl Delta (nos. WW2018231 and WW2018225), the Chinese National Natural Science Foundation (Grant nos. 51979017 and 51979021), and Major Projects of Chongqing Education Committee (Grant no. KJZD-M201900702).

\section{References}

[1] Y. Huang, Z. Fu, J. Chen, Z. Zhou, and J. Wang, "The external water pressure on a deep buried tunnel in fractured rock," Tunnelling and Underground Space Technology, vol. 48, pp. 58-66, 2015.
[2] Q. Zhang, D. Jia, Y. Bao, Z. Cheng, L. Xiao, and Y. Bu, "Internal force transfer effect-based fatigue damage evaluation for PBL shear connector groups," Journal of Constructional Steel Research, vol. 148, pp. 469-478, 2018.

[3] M. Claßen, "Limitations on the use of partial shear connection in composite beams with steel t-sections and uniformly spaced rib shear connectors," Journal of Constructional Steel Research, vol. 142, pp. 99-112, 2018.

[4] S.-H. Kim, S. Park, K.-S. Kim, and C.-Y. Jung, "Generalized formulation for shear resistance on y-type perfobond rib shear connectors," Journal of Constructional Steel Research, vol. 128, pp. 245-260, 2017.

[5] D. Lowe, K. Roy, R. Das, C. G. Clifton, J. B. P. Lim, and B. P. James, "Full scale experiments on splitting behaviour of concrete slabs in steel concrete composite beams with shear stud connection," Structures, vol. 23, pp. 126-138, 2020.

[6] W. Deng, M. Zhou, M. F. Hassanein, J. Zhang, D. Liu, and L. An, "Growth of prestressed concrete bridges with corrugated steel webs in China," Proceedings of the Institution of Civil Engineers-Civil Engineering, vol. 171, no. 2, pp. 77-84, 2018.

[7] W. Q. Deng, J. C. Gu, D. Liu, J. Hu, and J. D. Zhang, "Study of single perfobond rib with head stud shear connectors for a composite structure," Magazine of Concrete Research, vol. 71, no. 17, 2018.

[8] M. Shariati, N. H. Ramli Sulong, M. Suhatril, A. Shariati, M. M. Arabnejad Khanouki, and H. Sinaei, "Comparison of behaviour between channel and angle shear connectors under monotonic and fully reversed cyclic loading," Construction and Building Materials, vol. 38, no. 38, pp. 582-593, 2013.

[9] C. Zhao, Z. Li, K. Deng, and W. Wang, "Experimental investigation on the bearing mechanism of perfobond rib shear connectors," Engineering Structures, vol. 159, pp. 172-184, 2018.

[10] F.-x. Ding, G.-a. Yin, H.-b. Wang, L. Wang, and Q. Guo, "Static behavior of stud connectors in bi-direction push-off tests," Thin-Walled Structures, vol. 120, pp. 307-318, 2017.

[11] I. Viest, "Investigation of stud shear connectors for composite concrete and steel T-beams," ACI Journal Proceedings, vol. 52, no. 4, pp. 875-891, 1956.

[12] J. G. Ollgaard, R. G. Slutter, and J. W. Fisher, "Shear strength of stud connectors in lightweight and normalweight concrete," American Institute of Steel Construction, vol. 8, no. 2, pp. 55-64, 1971.

[13] K. Cederwall and A. Li, "Push-out tests on studs in high and normal strength concrete," Journal of Constructional Steel Research, vol. 36, no. 1, pp. 15-29, 1996.

[14] M. Clasen and J. Hegger, "Shear-slip behavior and ductility of composite dowel connectors with pry-out failure," Engineering Structures, vol. 150, pp. 428-437, 2017.

[15] M. Koop and K. Wolters, "Composite dowels as shear connectors for composite beams-background to the design concept for static loading," Journal of Constructional Steel Research, vol. 147, pp. 488-503, 2018.

[16] I. B. Valente and P. J. S. Cruz, "Experimental analysis of shear connection between steel and lightweight concrete," Journal of Constructional Steel Research, vol. 65, no. 10-11, pp. 19541963, 2004.

[17] P. C. G. D. S. Vellasco, S. A. L. D. Andrade, L. T. S. Ferreira et al., "Semi-rigid composite frames with perfobond and T-rib connectors Part 1: full scale tests," Journal of Constructional Steel Research, vol. 63, no. 2, pp. 263-279, 2007.

[18] S. A. L. D. Andrade, P. C. G. D. S. Vellasco, L. T. S. Ferreira et al., "Semi-rigid composite frames with perfobond and T-rib 
connectors Part 2: design models assessment," Journal of Constructional Steel Research, vol. 63, no. 2, pp. 280-292, 2008.

[19] I. Zemir, F. Debieb, S. Kenai et al., "Strengthening of ordinary vibrated concrete using steel fibers self-compacting concrete," Journal of Adhesion Science and Technology, vol. 34, no. 12, pp. 1-16, 2020.

[20] M. Pajak and T. Ponikiewski, "Flexural behavior of selfcompacting concrete reinforced with different types of steel fibers," Construction and Building Materials, vol. 47, pp. 397-408, 2013.

[21] GB/T 2975-2018, Steel and Steel Products-Location and Preparation of Samples and Specimens for Mechanical Testing, State Administration of market supervision and Administratio, Beijing, China, 2018, in Chinese.

[22] JGJ/T 98-2010, Specification for Mix Proportion Design of Masonry Mortar, China Architecture \& Building Press, Beijing, China, 2010, in Chinese.

[23] K. Maekawa and K.-I. Nakarai, "Multi-scale modeling of corroded reinforced concrete and soil foundation in shear," in Proceedings of the Abstracts of the Papers Presented at the Minisymposia0 Sessions of the Sixth World Congress on Computational Mechanics in Conjunction with the Second Asian-Pacific Congress on Computational Mechanics, Beijing, China, 2004. 